\title{
Modelling the potential of green and blue infrastructure to reduce urban heat load in the city of Vienna
}

\author{
M. Žuvela-Aloise ${ }^{1} \cdot$ R. Koch ${ }^{1} \cdot$ S. Buchholz ${ }^{2} \cdot$ B. Früh ${ }^{2}$
}

Received: 15 May 2015 / Accepted: 3 January 2016/Published online: 5 February 2016

C The Author(s) 2016. This article is published with open access at Springerlink.com

\begin{abstract}
The climate warming trend and city growth contribute to the generation of excessive heat in urban areas. This could be reduced by introducing vegetation and open water surfaces in urban design. This study evaluates the cooling efficiency of green and blue infrastructure to reduce urban heat load using a set of idealized case simulations and a real city model application for Vienna. The idealized case simulations show that the cooling effect of green and blue infrastructure is dependent on the building type, time of the day and in case of blue infrastructure, the water temperature. The temperature reduction and the size of the cooled surface are largest in densely built-up environments. The real case simulations for Vienna, which include the terrain, inhomogeneous land use distribution and observed climate data, show that urban planning measures should be applied extensively in order to gain substantial cooling on the city scale. The best efficiency can be reached by targeted implementation of minor but combined measures such as a decrease in building density of $10 \%$, a decrease in pavement by $20 \%$ and an enlargement in green or water spaces by $20 \%$. Additionally, the modelling results show that equal heat load mitigation measures may have different efficiency dependent on location in the city due to the prevailing meteorological conditions and land use characteristics in the neighbouring environment.
\end{abstract}

\section{Introduction}

Urban areas experience higher temperatures than their surroundings, a phenomenon known as the Urban Heat Island (UHI) effect. According to the IPCC climate projections (Christensen et al. 2007, 2013), the maximum summer temperature in southern and Central Europe is very

Electronic supplementary material The online version of this article (doi:10.1007/s10584-016-1596-2) contains supplementary material, which is available to authorized users.

M. Žuvela-Aloise

maja.zuvela-aloise@zamg.ac.at

1 ZAMG - Zentralanstalt für Meteorologie und Geodynamik, Vienna, Austria

2 DWD - Deutscher Wetterdienst, Offenbach, Germany 
likely to increase by the end of the 21st century. The temperature records at the monitoring station Hohe Warte, located in low density residential area of Vienna, show a warming trend with increase in mean annual number of summer days (SU: $\mathrm{T}_{\max } \geq 25^{\circ} \mathrm{C}$ ) from $52.1 \mathrm{SU}$ per year for the period 1961-1990 to 64.1 SU for the period 1981-2010. Possible expansion of the urban area, as well as the expected climate warming, could contribute to the excessive formation of urban heat and further increase the observed warming trend. The health risks related to the extreme heat may pose a considerable problem for the city dwellers in the future (Schär et al. 2004; Souch and Grimmond 2004; Fischer and Schär 2010). Hence, heat load mitigation strategies in urban planning have an increasing interest.

Numerous concepts have been developed to mitigate the heat load in urban areas, such as customizing urban vegetation for shading and evaporative cooling (Spronken-Smith and Oke 1998; Solecki et al. 2005; Gill et al. 2007; Memon et al. 2008; Bowler et al. 2010; Oliveira et al. 2011; Fallmann et al. 2014), introducing open water surfaces (Hathway and Sharples 2012; Theeuwes et al. 2013), planning of built structures that support ventilation by choosing an appropriate geometry and size of buildings and street areas (Ali-Toudert and Mayer 2007a, b; Middel et al. 2014), and applying suitable materials and colours for buildings to reduce the heat storage and the absorption of solar radiation (Hamdi and Schayes 2008; Krayenhoff and Voogt 2010; Santamouris et al. 2012). Increase in vegetation and water surfaces, known as green and blue infrastructure, is of particular interest due to their multiple functionality and benefits for the urban environment, such as increasing urban biodiversity and improving air quality in case of urban vegetation (Akbari et al. 2001). However, little is known about the efficiency of blue and green infrastructure in reduction of heat load when applied on a city scale. Moreover, it is unclear to which extent these measures need to be implemented to have a substantial effect which could counteract the observed warming trend.

The goal of the modelling is study is to evaluate the cooling potential of the blue and green infrastructure to reduce the UHI effect when applied to large areas of the city. The key focus and the novelty of the study is to evaluate effects of vegetation and open water surfaces on the built-up environment when taking into account elevation, inhomogeneous urban fabric and impacts of the surroundings by explicit consideration of advection allowing interaction between the neighbouring surfaces. Due to the advection in the model the air-masses can be transferred between the grid cells. In that way the cooling effect is not restricted to the modified surface, but can be transported to neighbouring areas dependent on the wind speed and direction. Due to complexity of the processes involved, the modelling study is separated in two parts: 1) idealized case simulations which analyse the heat reduction in a simplified model set-up and 2) real case simulations applying the model for the city of Vienna using high resolution terrain and land use data. Although a large number of thermal urban climate studies with a focus on climate adaptation are available, the results are difficult to compare, difficult to transfer to other real world examples and, even more important, difficult to standardize. The concept of idealized case and systematic modelling provides the opportunity to draw more general conclusions for urban planning, rather than relying on single case studies. Because they can provide a database for different urban quarters/building structures and the effectiveness of adaptation measures for varying degrees of implementation. The approach of idealized case modelling provides the opportunity to draw more general conclusions due to the systematic experiment structure. The heterogeneity of the urban land cover is limited to a minimum ( 2 or 3 land use classes) in order to analyse only the quantitative impact of individual or combined adaptation measures on urban climate. In the real case simulations effects of terrain and actual spatial distribution of land use, as well as observed meteorological conditions 
are included and the simulations have therefore an applied purpose. The study uses the urban climate model MUKLIMO_3 and the method for calculation of climate indices called the "cuboid method" (Früh et al. 2011) which is a recently developed approach to evaluate heat load changes on a longer temporal timescales (see Appendix A). The real case simulations for Vienna include eight cuboid corners and are later combined with the climatological data, while the idealized simulations are only performed for two of the eight cuboid corners (warm, dry and weak wind, as well as warm, dry and windy conditions) and are used for the analysis of hourly fields of meteorological variables. This study is intended as a supporting and guidance tool for urban planning and policy consulting under climate change conditions to enhance the wellbeing of the city population.

\section{Methodology}

\subsection{Idealized case simulations}

The model domain for the idealized case simulations with urban parks and water is a $60 \times 60$ grid with $100 \mathrm{~m}$ horizontal grid spacing. An overview of the modelling simulations is given in Table A1. Four parks or water areas with an equal size of 25 ha are evenly distributed within the centre of the model with a separation of $1 \mathrm{~km}$ in the $\mathrm{x}$ - and $\mathrm{y}$-direction to account for possible interaction between the next park or water area. Simulations were carried out for the meteorological boundary conditions of the cuboid corners which represent warm, dry, and weak wind conditions $\left(\mathrm{T}_{\mathrm{cmax}}=25^{\circ} \mathrm{C}, \mathrm{rh}_{\mathrm{cmin}}=42 \%, \mathrm{v}_{\mathrm{cmin}}=0.7 \mathrm{~m} / \mathrm{s}\right)$, as well as warm, dry, and windy conditions $\left(\mathrm{T}_{\mathrm{cmax}}=25^{\circ} \mathrm{C}, \mathrm{rh}_{\mathrm{cmin}}=42 \%, \mathrm{v}_{\mathrm{cmax}}=4 \mathrm{~m} / \mathrm{s}\right)$. The geographical coordinates and land use classes correspond to the application for the Vienna model. Besides the park and water surfaces, the remaining grid cells of the model have the identical land use class, which is either sparse residential area (LU1) representative for Vienna suburban areas, or medium dense residential area (LU3) representative for the Vienna city centre. The urban park is simulated with a tree density of $28 \%$. The trees are evenly distributed over all types of underlying surfaces, which are $18.0 \%$ impervious surface, $2.7 \%$ bare soil and $51.3 \%$ low canopy vegetation. Two simulations, LU1 and LU3, without any park or water area serve as reference runs for comparison. To examine the impact of different water temperatures on the urban climate, simulations were performed for two water temperatures, $18{ }^{\circ} \mathrm{C}$ and $23^{\circ} \mathrm{C}$ which span the range of possible water temperatures during the summer months. The impact of the heat load mitigation measures refer, if not mentioned otherwise, to the temperature changes within the built-up surroundings. All simulations were performed for flat terrain. To minimize the influence of boundary effects on the urban climate, the first 5 boundary grid cells in each direction were excluded from the evaluation.

\subsection{Model application for Vienna}

The domain size used for Vienna covers an area of $31 \mathrm{~km} \times 24 \mathrm{~km}$ using an equidistant grid with $100 \mathrm{~m}$ horizontal resolution. The 1D model has 52 levels and reaches the height of $2000 \mathrm{~m}$, while the 3D model has a height up to $1000 \mathrm{~m}$ above the sea level and 39 levels. The vertical resolution in the $3 \mathrm{D}$ model varies from 10 to $50 \mathrm{~m}$ with higher resolution near the ground and is higher than the vertical resolution used in similar modelling studies (e.g. Fallmann et al. 2014). The Digital Elevation Model (DEM) which is used as model input is 
provided by the BEV ("Bundesamt für Eich- und Vermessungswesen" - Federal Office of Metrology and Surveying). The land use dataset is obtained by merging two datasets: satellitebased ARCSYS dataset with raster resolution of $100 \mathrm{~m}$ (Steinnocher 1996) and the high resolution dataset with minimum polygon area of 0.2 ha provided by the city administration of Vienna (MA 18 - Urban Development and Planning), as shown in Fig. 1. The combined dataset has 32 different land use types. The land use parameters are derived from a technical description of typical building structures in Germany (BMBAU 1980) and are adjusted for Vienna based on the supplementary data provided by the Austrian Institute of Technology. The spatial distribution of impervious surfaces, buildings and vegetation used to estimate mean values of the parameters for each land use category is given in Appendix (Figure A1). The simulations for eight cuboid corners were performed for two prevailing wind directions: northwest and southeast. Time series of $T$, $r h$ and $v$ for the period 1981-2010 from the monitoring station Groß Enzersdorf (GE) located in the rural environment eastward of Vienna were used to calculate the climatic indices for all simulations. Meteorological data used in the cuboid method and an example of parameter values for various land use classes in Vienna is given in Žuvela-Aloise et al. (2014). Observational data for daily maximum temperature from 7 monitoring stations with more than 10 years of measurements $(\mathrm{HW}=$ Hohe Warte, IS = Innere Stadt, $\mathrm{MB}=$ Mariabrunn, $\mathrm{UL}=$ Unterlaa, $\mathrm{DF}=$ Donaufeld, $\mathrm{SC}=$ Schwechat $)$ including the station GE were used for the model evaluation.

A set of sensitivity simulations with altered land use characteristics including a decrease in pavement and building density, a systematic change of vegetation fraction, an increase in vegetation only on specific locations such as traffic corridors and residential districts, the placement of new parks on defined locations and an increase in water areas were modelled (Table A1). In the model setup, the City of Vienna (political borders) covers an area of $41,572 \mathrm{ha}$, of which $50 \%(20,614 \mathrm{ha})$ is built up area including traffic (14.4\% or $6000 \mathrm{ha})$; $2.8 \%$ (1157 ha) are city parks; $4.6 \%$ (1915 ha) are water surfaces and the remaining percentage is covered by forest or used for agriculture.

\section{Results and discussion}

\subsection{Model validation for Vienna}

The modelling results for the period 1981-2010 indicate a complex spatial structure of the urban heat load in Vienna (Fig. 1c). The maximum heat load is found in densely built-up areas in the city centre and in residential areas with flat terrain north-east of the Danube river. Both terrain and land use distribution influence the spatial characteristics of the urban heat load. The spatial pattern of the UHI in Vienna based on the land use distribution is characterized by the pronounced gradient between the urban centre, the forest area to the west and agricultural areas in the east and south. Due to the elevation and prevailing winds from the northwest and southeast, the same type of built-up areas have different heat load. In the residential areas located on the hill slopes to the west the heat load is lower than in the flat terrain located to the south and east of the city centre.

The number of SU is calculated for each year for the time period 1981-2010 and the model performance is given in Table 1. Mean annual number of SU derived by the modelling approach shows good agreement when compared to observational data at the monitoring stations. However, validation of the meteorological fields provided by the high resolution 
model remains a problem due sparse and irregularly spaced observations, especially when long-term measurements are concerned. To account for the inhomogeneous environment and possible land use mismatches in the model, the modelling data are evaluated at the nearest neighbouring point, at the representative land use surface and as the mean within a radius of $150 \mathrm{~m}$ from the monitoring station. The deviations are less than $10 \%$ from observational values except for the station MB that shows better agreement when the surrounding area is taken into account.

The dynamical core of the MUKLIMO_3 model is based on the Reynolds-Averaged Navier-Stokes equations (RANS model). Unlike mesoscale models with LES capability (e.g. Weather Research \& Forecasting Model - WRF) that have the turbulence representation dependent on the grid resolution, the turbulence parameterization in RANS models includes the full spectrum of boundary layer turbulence regardless of the spatial scale of the model grid (Fröhlich and von Terzi 2008). While the question of appropriate turbulence parameterization in the "Terra Incognita" or the so called "grey-zone" problem (Wyngaard 2004) is justified for high resolution simulations, it cannot be easily solved for RANS-type models. The error induced by the application of the turbulence scheme such as overestimation of the turbulence mixing, remain part of the model uncertainty. Nevertheless, RANS models are still the most common approach for the microscale simulations in the urban environments (Franke et al. 2007; Moonen et al. 2012). The reason is their computational efficiency and development of models towards practical engineering applications. Observational studies show that using the MOST and the Blackadar's formula for mixing length generally overestimate the turbulent mixing for heights more than $20 \mathrm{~m}$ above the ground (Sun 2011). Therefore, the implementation of a more sophisticated turbulence scheme in MUKLIMO_3 is recommended for further research. While this may improve the modelling results in certain cases, it should be noted that it does not necessarily solve the "grey-zone" problem, which requires grid spacing dependent calculation of turbulent fluxes.

\subsection{The cooling effect of park and water surfaces in idealized case simulations}

Inclusion of four park areas in low density residential and dense built-up areas leads to temperature reduction of the built-up surroundings during the day and night time (Fig. 2, top). The temperature differences are higher in the low wind speed model run compared to the windy model run. The maximum temperature reduction $\left(<-1^{\circ} \mathrm{C}\right)$ is simulated in the evening hours for both types of urban structure. This phenomenon often called the Park Cool Island effect is particularly pronounced during clear and calm nights (Spronken-Smith and Oke 1998; Upmanis et al. 1998) and is a result of evaporative cooling, shading and thermal admittance (Spronken-Smith and Oke 1999; Oliveira et al. 2011). In general, the highest temperature reductions occur close to the park areas. The maximum area with lower temperatures in the low density residential district is simulated after sunset (447 ha), whereas the maximum area with lower temperatures in the densely built-up neighbourhoods is simulated during the night (708 ha). With the exception of the evening hours, the temperature reduction and size of the cooled densely built-up area is higher than the temperature reduction and size of the cooled low density residential area.

Water areas (e.g. ponds, lakes and rivers) influence the urban climate by cooling and warming depending on the water temperature, built-up environment, time of day and wind conditions. In general, the cooling of the surrounding built-up environment is more pronounced for water areas with a water temperature of $18{ }^{\circ} \mathrm{C}$ than for parks (Fig. 2, centre). 


\section{a}

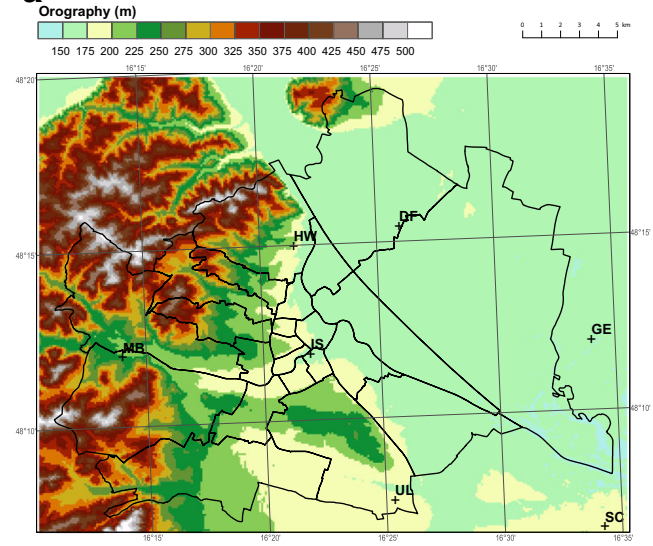

b

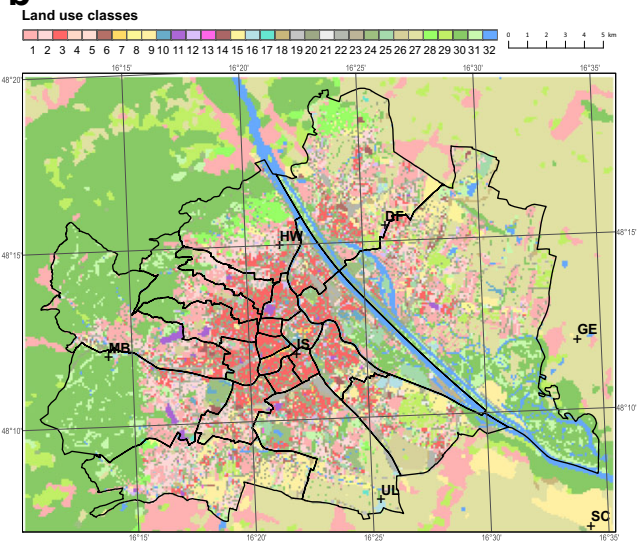

C

Mean annual number of summer days

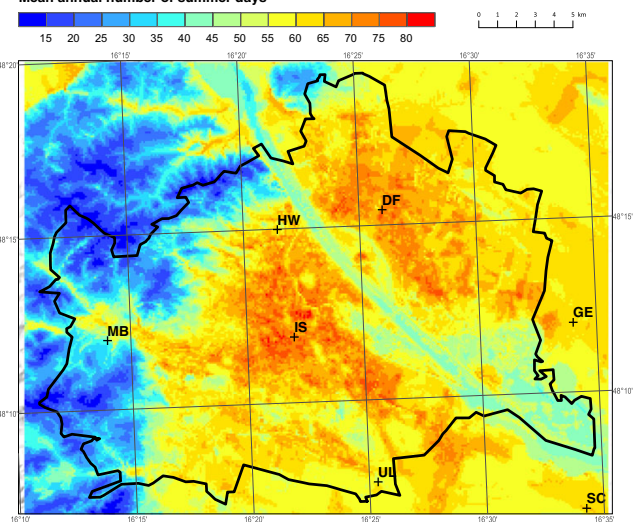

Fig. 1 Elevation (a) and land use distribution (b) in Vienna and its surroundings provided by the Vienna city administration (Wien MA18) and combined with the satellite-based land use dataset for Austria (Steinnocher 1996). Mean annual number of SU in Vienna calculated with the urban climate model MUKLIMO_3 and the "cuboid method" based on the climatic data for the period 1981-2010 (c). Labels indicate locations of climate stations used in evaluation: $\mathrm{HW}=$ Hohe Warte, IS $=$ Innere Stadt, $\mathrm{MB}=$ Mariabrunn, UL $=$ Unterlaa, $\mathrm{DF}=$ Donaufeld, $\mathrm{GE}=\mathrm{Gro}$ Enzersdorf, $\mathrm{SC}=$ Schwechat 
This refers to both the achieved temperature reductions and the size of the effected builtup area. Especially, during the day the achieved temperature reductions in the built-up environment are maximum $1.75{ }^{\circ} \mathrm{C}$ for water areas and $1.25{ }^{\circ} \mathrm{C}$ for park areas. At 14 CEST (12 UTC) for the model run with low wind speed conditions and the four water areas at $18{ }^{\circ} \mathrm{C}$, there are lower near surface air temperatures over 448 ha in the low density residential area and 716 ha in the dense built-up area. For parks, the cool areas were 165 ha for low density residential and 393 ha of the dense built-up type. During evening hours the cooling effect of water areas with a water temperature of $18{ }^{\circ} \mathrm{C}$ and parks is similar under low wind conditions, but it is higher for water areas in windy conditions. Different spatial extension of the cooled built-up area can be related to the temperature of the air mass that is advected from the park or the water surface. Implementation of new vegetation or water surface in densely built-up areas produces a higher temperature gradient than the same modification applied in the low density built-up. The higher the temperature differences between the water area $\left(18{ }^{\circ} \mathrm{C}\right.$ and $23^{\circ} \mathrm{C}$ ) and the air temperature in the built-up surrounding, the higher is the cooling effect (Theuwees et al. 2013). Water areas with a water temperature of $23{ }^{\circ} \mathrm{C}$ show a cooling effect on the built-up surrounding as well, particularly during the day and after sunset (Fig. 2, bottom). If the water temperature is similar to or exceeds the near surface air temperature of the built-up surrounding, which is the case during the night hours for the low density residential area and the low wind conditions and for both building types for high wind conditions, the water areas warm the surrounding built-up environment.

\subsection{Real case simulations for Vienna}

The reduction of heat load in the model application for Vienna is expressed as the difference in mean annual number of SU between the sensitivity simulation and the reference model run. Using a long-term monitoring time series of daily $\mathrm{T}_{\max }$ and mean monthly temperature, the annual number of SU can be correlated with the mean temperature in summer months (June, July, August). In Vienna, the change in mean summer temperature of $1{ }^{\circ} \mathrm{C}$ corresponds to a difference of 12.2 SU (Zuvela-Aloise et al., 2014). The reduction of heat load by $-6 \mathrm{SU}$ in annual mean is, therefore, equivalent to a cooling effect in mean summer temperature of approximately $-0.5{ }^{\circ} \mathrm{C}$. The heat load difference of less than $1 \mathrm{SU}$ (equiv. to approximately $0.1^{\circ} \mathrm{C}$ ) is considered to be below the model accuracy.

The simulation "BFrac" (Fig. 3a and b) in which the building fraction is decreased by $10 \%$ in all built-up areas shows a reduction of heat load in $70 \%$ of the city area. The cooling effect is mostly minor (average over the city is $-2.5 \mathrm{SU}$, maximum of about $-10 \mathrm{SU}$ ) and $4 \%$ of the city area (1596 ha) has at least -6 SU. Decreasing the building density by $10 \%$ reduces the heat load more than decreasing the fraction of pavement by $20 \%$.

The "GreenCor" simulation (Fig. 3c and d) in which traffic areas have $20 \%$ more vegetation, building density is decreased by $10 \%$ and pavement is decreased by $20 \%$, shows a cooling effect $(\leq-1 \mathrm{SU})$ on $42 \%$ of the city area $(17,488 \mathrm{ha})$. The reduction of heat load is smaller than in the "BFrac" simulation $(-1.2 \mathrm{SU}$ average over the city, maximum of about $-7 \mathrm{SU})$. However, the effected surface is three times larger than the modified surface. This simulation indicates the potential of spreading the cooling effect on the surrounding areas if the mitigation measures are applied uniformly throughout the city. 


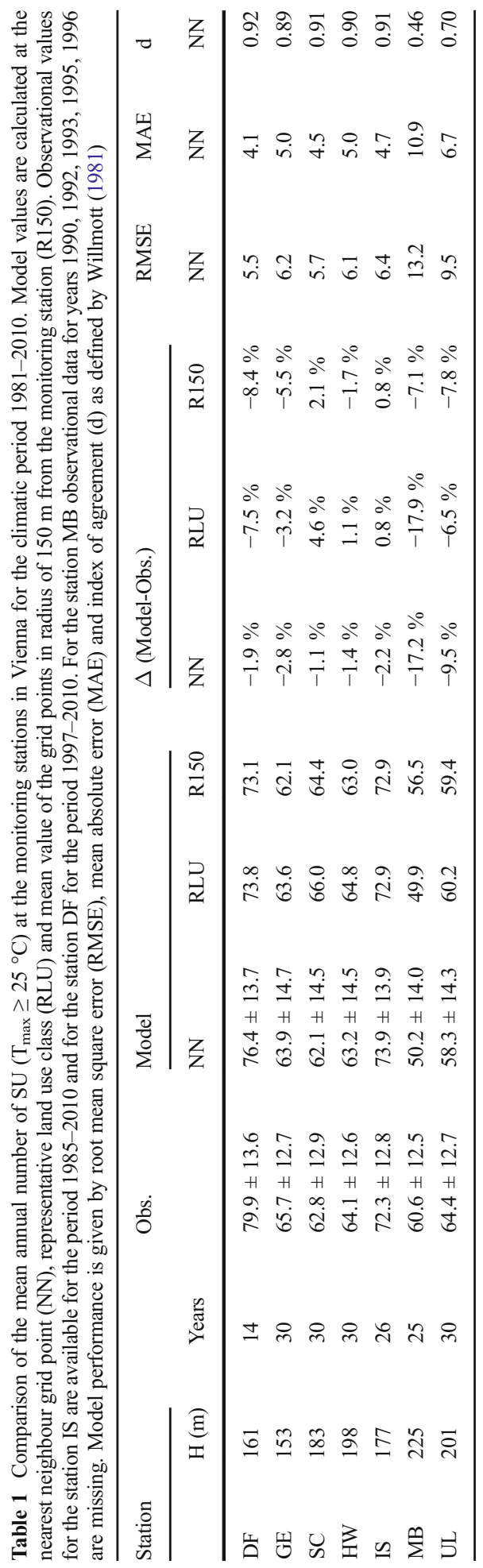



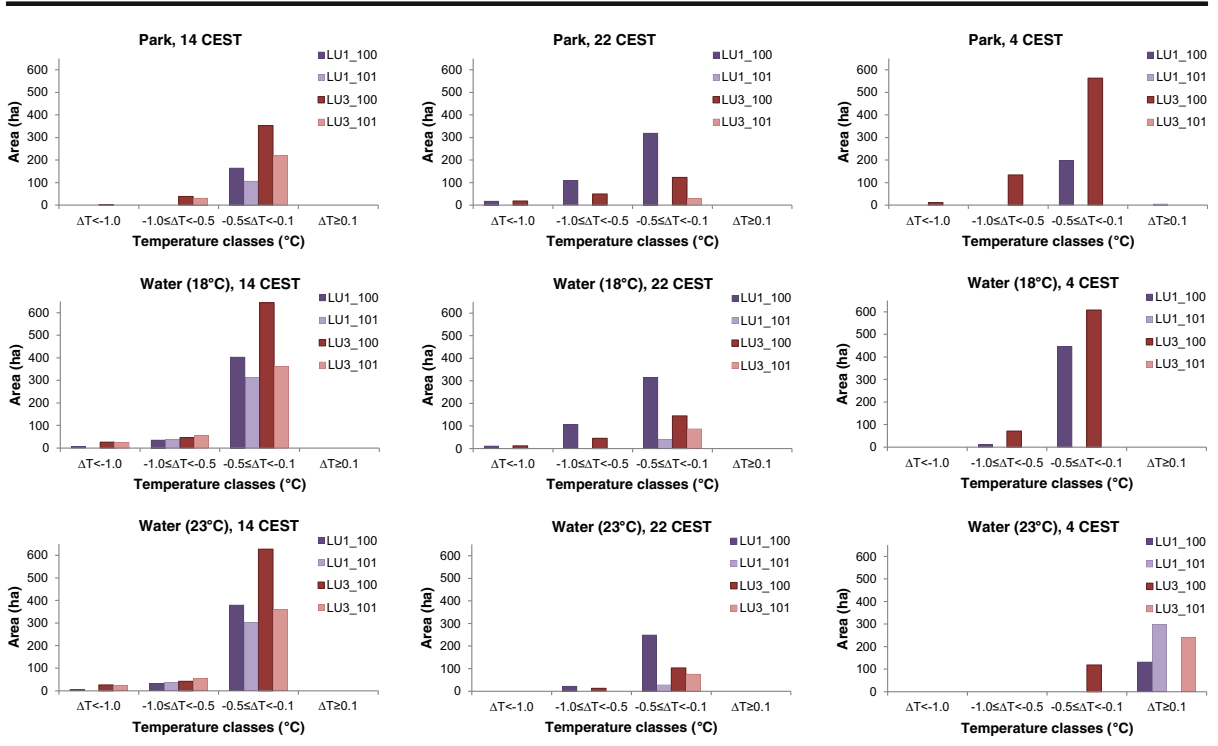

Fig. 2 Air temperature changes of effected areas (ha) at different times of the day for low density residential (LU1) and dense built-up (LU3) due to four included park and water areas (with water temperatures of $18{ }^{\circ} \mathrm{C}$ and $23^{\circ} \mathrm{C}$ ) in simulations with low (100) and high wind speed conditions (101). The temperature changes between $-0.1^{\circ} \mathrm{C}$ and $0.1^{\circ} \mathrm{C}$ are regarded as insignificant change and are not included in the figure

The cooling effect is spread over the city and the intensity of the heat load reduction increases (Fig. 3e and f) if the same modifications in land use as in "GreenCor" are applied to residential areas as well ("GreenCor + Res"). In this simulation, $81 \%$ of the city area shows a cooling effect ( $\leq-1 \mathrm{SU}$ ) with $19 \%$ of the city area having reduced heat load by at least $-6 \mathrm{SU}$. Heat load in the city is reduced by $-3.4 \mathrm{SU}$ on average over the city. Maximum cooling $(\leq-10 \mathrm{SU})$ is found in the residential districts where the modifications are largely applied.

The possibilities of optimal positioning of city parks that will produce highest cooling effects (new parks vs. enlargement of existing parks, small vs. large parks, scattering vs. agglomeration of parks) and replacing park areas with water surfaces is investigated, while considering that the implementation of new green areas in densely built environment is generally difficult to realize. Figure 4 shows the heat load reduction from increasing the park and water area at different locations in the city. Two simulations are performed in which the park area is increased by $30 \%$. In "ParkIn", the new parks are concentrated in the inner city (Fig. 4a) and in "ParkOut" (Fig. 4c), the parks are scattered outside of the city centre. Both simulations show a reduction of heat load in the vicinity of the parks. However, in the "ParkIn" the cooling effect is larger and the cooling spreads to the near-by built-up areas. For 347 ha of new parks, the reduction of heat load $(\leq-1 \mathrm{SU})$ is found in 4791 ha of surrounding areas. The cooling effect to the northwest and southeast of the modified region is a result of the cool air advection by the prevailing winds. The maximum cooling $(<-15 \mathrm{SU})$ is found in the parks themselves. Heat load reduction of $-6 \mathrm{SU}$ or more occurs on 258 ha, from which 44 ha are outside of the parks. In contrast, "ParkOut" shows mostly cooling in parks. The area outside of the parks with reduced heat load $(\leq-1$ $\mathrm{SU})$ is smaller ( $810 \mathrm{ha}$ ), but the intensity of cooling is higher (126 ha with heat load reduction of $-6 \mathrm{SU}$ or more) than in "ParkIn". The modelling results show that the cooling 


\section{a}

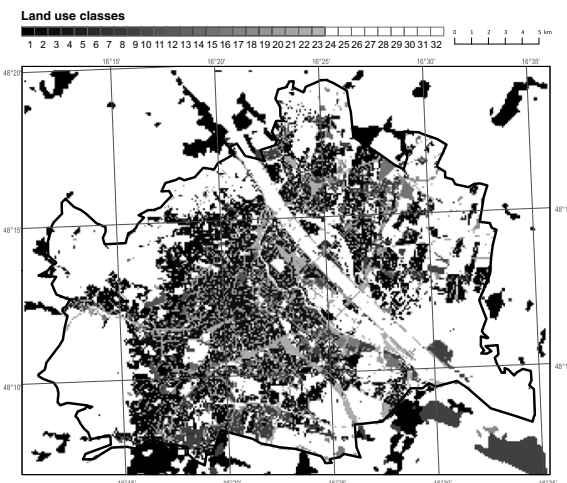

C

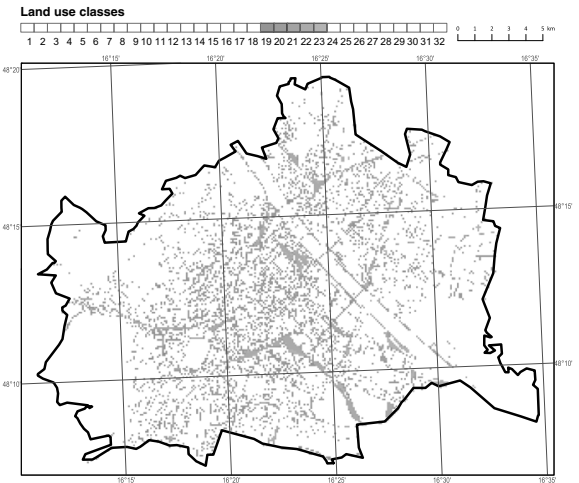

e
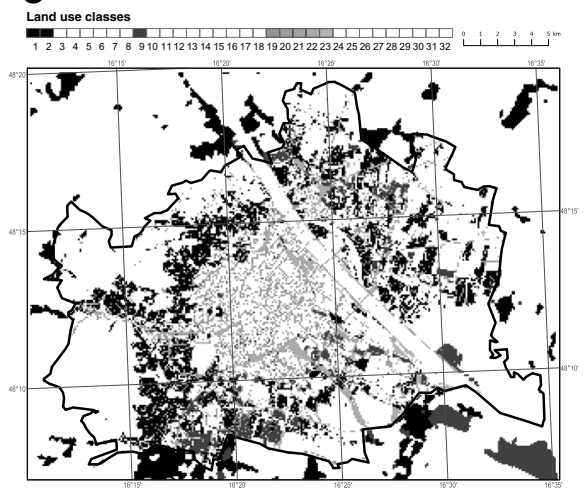

b

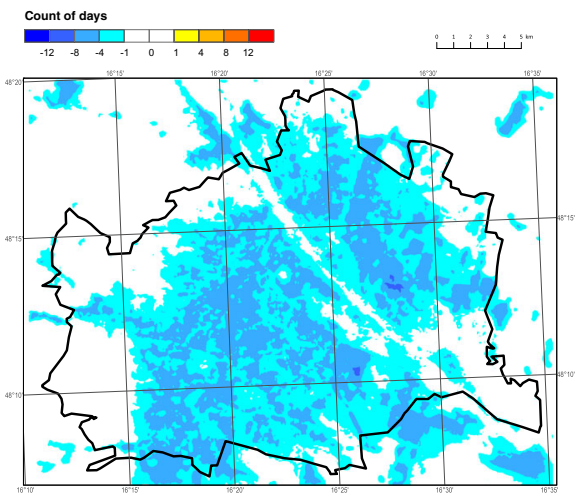

d

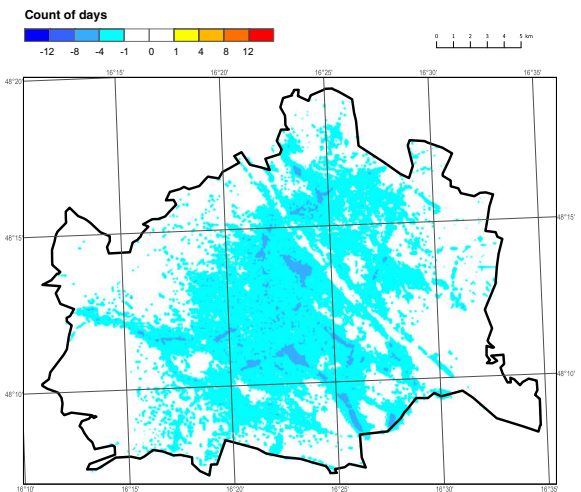

f

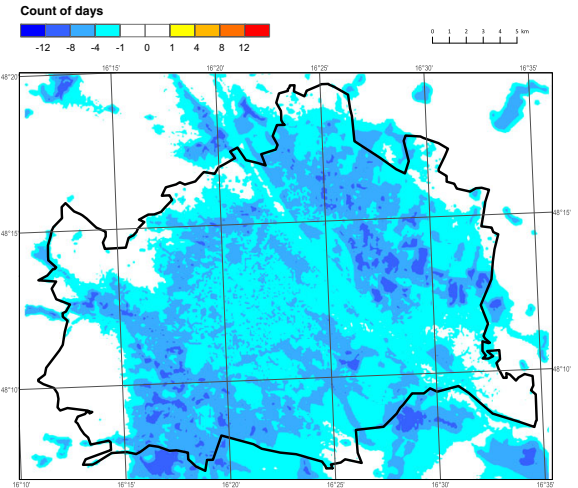

Fig. 3 Modified land use (left) and difference in mean annual number of days with $\mathrm{T}_{\max } \geq 25^{\circ} \mathrm{C}(\mathrm{SU})$ compared to the reference simulation (right) in the simulation with $10 \%$ reduction of building density (a, b), green traffic areas (c, d) and green residential and traffic areas $(\mathbf{e}, \mathbf{f})$. Modifications in land use for green scenarios include lowering building density by $10 \%$, fraction of pavement by $20 \%$ and increasing tree and low vegetation fraction by $20 \%$

intensity and the influence on the surrounding area are dependent on the size and location of the modified surface as well as on the previous land use characteristics. For example, large green areas produce stronger cooling effects in the location of the park itself. 


\section{a}
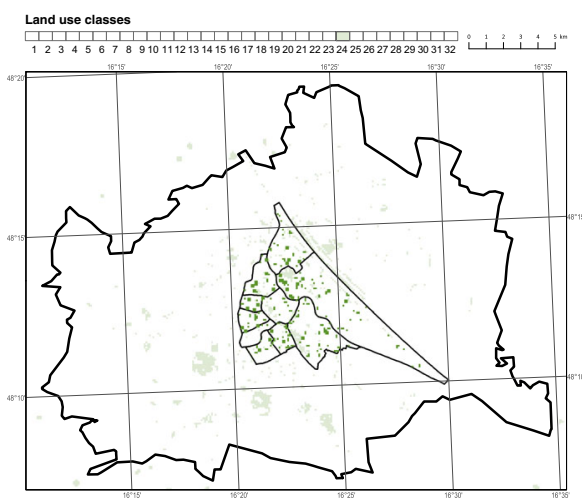

\section{C}

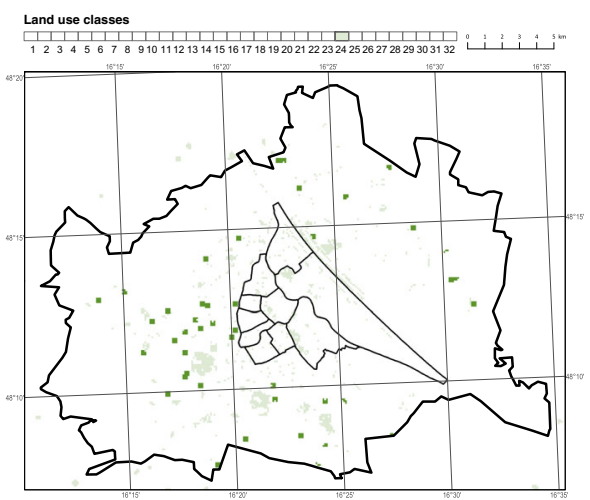

e
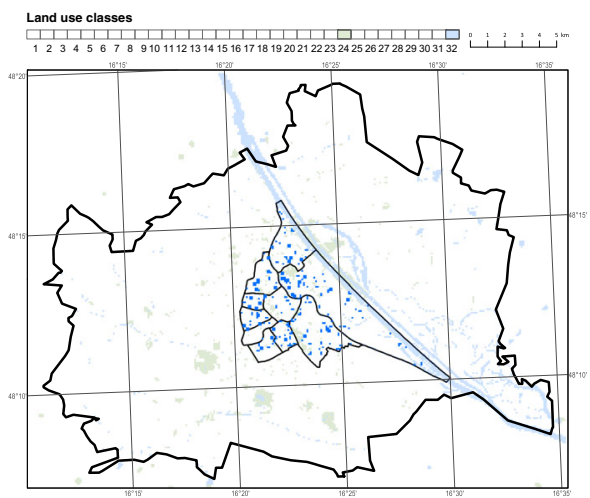

b

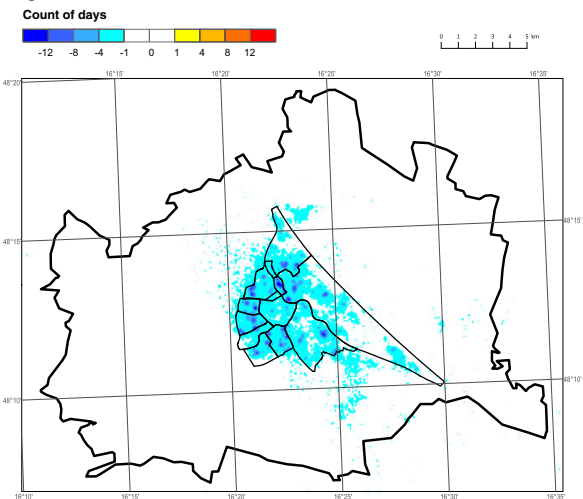

d

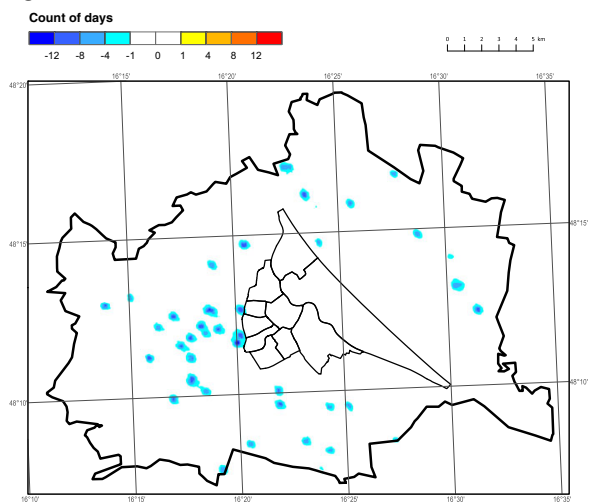

f

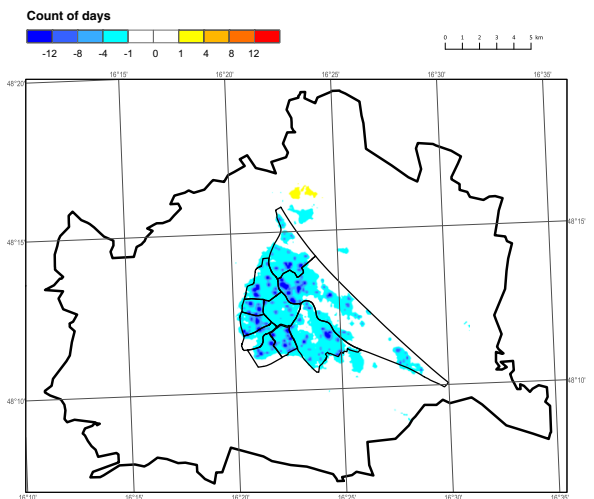

Fig. 4 Modified land use (left) and difference in mean annual number of days with $\mathrm{T}_{\max } \geq 25^{\circ} \mathrm{C}$ (SU) compared to the reference run (right) in the simulation with $30 \%$ increase of park areas in the city centre (a, b), outside of the city centre $(\mathbf{c}, \mathbf{d})$ and increase in water surfaces instead of parks in the city centre $(\mathbf{e}, \mathbf{f})$

However, the cooling effect on the surroundings is dependent on the building density, vicinity of other green or water spaces and the prevailing air circulation that can enhance entrainment of cool air. 
A similar simulation as for the vegetation is performed replacing the modified park areas with water ("WaterIn"). Existing water surfaces were left unchanged (Fig. 4e). The modelling results show a moderate to strong cooling effect during the daytime with maximum cooling over $-20 \mathrm{SU}$ (Fig. 4f). The heat load reduction ( $\leq-1 \mathrm{SU})$ occurs on 2874 ha excluding the water surfaces and 129 ha have a heat load reduction of $-6 \mathrm{SU}$ or more. In the simulation with higher water temperatures $\left(23{ }^{\circ} \mathrm{C}\right)$ the cooling effect is lower, which is consistent with the idealized case simulations.

\section{Conclusions}

The study investigates the cooling effect of vegetation and open water areas in urban environments by performing idealized model simulations and applying the modelling approach for the City of Vienna. The idealized case simulations for simplified urban structure show cooling effects and temporal variability in temperature in accordance with previous Findings. maximum reduction in air temperature of about $1{ }^{\circ} \mathrm{C}$ in simulations with increase in vegetation is comparable to numerical simulations by Hamdi and Schayes (2008); Gross (2012) and Fallmann et al. (2014). The idealized case simulations with water areas show temperature changes similar to idealized experiments by Theuwees et al. (2013) with warming effects at night dependent on the water temperature. The characteristics of the built-up environment, time of day and wind conditions influence the resulting cooling. The higher the temperature gradient between the green or water area and the built-up surrounding, the larger the intensity and spatial extension of the cooling.

The model simulation for Vienna shows a similar spatial distribution of urban heat load as found in observational data (Auer et al. 1989). The simulations with green infrastructure in the realistic model run show that the substantial reduction in temperature is achieved only by incorporating an extensive amount of vegetation. Heat load mitigation measures should be applied extensively in order to reach substantial reduction in urban heat load on a city scale. However, due to interaction with the surroundings, minor cooling effects often can be found outside the modified areas, especially if the mitigation measures are distributed evenly across the city (for example traffic corridors). If only critical areas with the highest heat load are considered, urban planning measures could be optimized through targeted and combined implementation. With the application of several heat load mitigation measures such as decrease in building density by $10 \%$ and pavement by $20 \%$, enlargement in green and water spaces by $20 \%$, it is possible to achieve substantial cooling effect with heat load reduction of $-10 \mathrm{SU}$ or more with a relatively small change in infrastructure.

The results from both the idealized and real-case simulations show that the temperature reduction due to implementation of green and blue infrastructure in urban areas is dependent on multiple factors. The real case simulations show that the terrain, prevailing wind direction and wind conditions, neighbouring areas and the size of the applied measures, influence the cooling effect. The dependence on local characteristics has been confirmed by observational studies as well (Spronken-Smith and Oke 1998, 1999; Upmanis and Chen 1999; Skoulika et al. 2014; Steeneveld et al. 2014). Hence, the same urban planning measure may have different effects in different locations in the city and the surrounding areas could amplify or dampen the cooling effect. By concentrating the parks in the city centre, the cooling effect could be amplified as compared to location parks in the low density residential areas in the outer districts of the city. 
The study demonstrates the potential of green and blue areas to mitigate the heat load. They are found to be especially effective in cooling dense built-up areas. Implementing large amount of greenery as well as new water surfaces in the actual urban situation is hard to implement in real urban planning efforts. However, the modelling study indicates the main processes which should be taken into account when implementing the heat load mitigation measures, such as expected cooling intensity, potential spatial extent, diurnal variability, type and size of implementation measures and possible dependence on the surrounding land use and terrain characteristics. While the results from idealized case simulations can serve for comparison with other methodologies and applications in different urban environments, the real city application for Vienna emphasizes the importance of addressing local characteristics in appropriate urban planning.

Acknowledgments The authors thank MSc David Neil Bird for his kind help in editing the English writing. This work was supported by the Austrian Climate Research Program (ACRP) under the Climate and Energy Fund framework (Project FOCUS-I No. B060373). The authors would like to thank the Vienna City administration (MA18) for providing the high resolution elevation and land use data and the Austrian Institute of Technology for making available and processing the supplement data.

Open Access This article is distributed under the terms of the Creative Commons Attribution 4.0 International License (http://creativecommons.org/licenses/by/4.0/), which permits unrestricted use, distribution, and reproduction in any medium, provided you give appropriate credit to the original author(s) and the source, provide a link to the Creative Commons license, and indicate if changes were made.

\section{References}

Akbari H, Pomerantz M, Taha H (2001) Cool surfaces and shade trees to reduce energy use and improve air quality in urban areas. Sol Energy 70(3):295-310

Ali-Toudert F, Mayer H (2007a) Effects of asymmetry, galleries, overhanging façades and vegetation on thermal comfort in urban street canyons. Sol Energy 81:742-754

Ali-Toudert F, Mayer H (2007b) Thermal comfort in an east-west oriented street canyon in Freiburg (Germany) under hot summer conditions. Theor Appl Climatol 87:223-237

Auer I, Böhm R, Mohnl H (1989) Klima von Wien; Eine anwendungsorientierte Klimatographie. Wien: Magistrat der Stadt Wien, 270 Seiten (=Beiträge zur Stadtforschung, Stadtentwicklung und Stadtgestaltung 20

BMBAU (1980) Wechselwirkungen zwischen der Siedlungsstruktur und Wärmeversorgungs-systemen. Schriftenreihe Raumordnung 06.044, Forschungsprojekt BMBau RS II 4-70 41 02-77. 10

Bowler DE, Buyung-Ali L, Knight TM ans AS Pullin (2010) Urban greening to cool towns and cities: a systematic review of the empirical evidence. Landsc Urban Plan 97:147-155

Christensen, J.H., B. Hewitson, A. Busuioc, A. Chen, X. Gao, I. Held, R. Jones, R.K. Kolli, W.-T. Kwon, R. Laprise, V. Magaña Rueda, L. Mearns, C.G. Menéndez, J. Räisänen, A. Rinke, A. Sarr and P. Whetton (2007) Regional Climate Projections. In: Climate Change 2007: The Physical Science Basis. Contribution of Working Group I to the Fourth Assessment Report of the Intergovernmental Panel on Climate Change [Solomon, S., D. Qin, M. Manning, Z. Chen, M. Marquis, K.B. Averyt, M. Tignor and H.L. Miller (eds.)]. Cambridge University Press, Cambridge, United Kingdom and New York, NY, USA

Christensen, J.H., K. Krishna Kumar, E. Aldrian, S.-I. An, I.F.A. Cavalcanti, M. de Castro, W. Dong, P. Goswami, A. Hall, J.K. Kanyanga, A. Kitoh, J. Kossin, N.-C. Lau, J. Renwick, D.B. Stephenson, S.-P. Xie and T. Zhou (2013): Climate Phenomena and their Relevance for Future Regional Climate Change. In: Climate Change 2013: The Physical Science Basis. Contribution of Working Group I to the Fifth Assessment Report of the Intergovernmental Panel on Climate Change [Stocker, T.F., D. Qin, G.-K. Plattner, M. Tignor, S.K. Allen, J. Boschung, A. Nauels, Y. Xia, V. Bex and P.M. Midgley (eds.)]. Cambridge University Press, Cambridge, United Kingdom and New York, NY, USA, pp. 1217-1308

Fallmann J, Emeis S, Suppan P (2014) Mitigation of urban heat stress - a modelling case study for the area of Stuttgart. Erde J Geogr Soc Berlin 144:202-216

Fischer EM, Schär C (2010) Consistent geographical patterns of changes in high-impact European heatwaves. Nat Geosci 3:398-403 
Franke, J., Hellsten, A., Schlünzen, H. and Carissimo, B. (Eds), (2007) Best practice guideline for the CFD simulation of flows in the urban environment. COST Action 732, report ISBN: 3-00-018312-4, $51 \mathrm{pp}$

Fröhlich J, von Terzi D (2008) Hybrid LES/RANS methods for the simulation of turbulent flows. Prog Aerosp Sci 44:349-377

Früh B, Becker P, Deutschländer T, Hessel J-D, Kossmann M, Mieskes I, Namyslo J, Roos M, Sievers U, Steigerwald T, Turau H, Wienert U (2011) Estimation of climate-change impacts on the urban heat load using an urban climate model and regional climate projections. J Appl Meteorol Climatol 50:167-184

Gill SE, Handley JF, Ennos AR, Pauleit S (2007) Adapting cities for climate change: the role of the green infrastructure. Built Environ 33:115-133

Gross G (2012) Effects of different vegetation on temperature in an urban building environment. Micro-scale numerical experiments. Met Zeit 21(4):399-412

Hamdi R, Schayes G (2008) Sensitivity study of the urban heat island intensity to urban characteristics. Int J Climatol 28:973-982

Hathway EA, Sharples S (2012) The interaction of rivers and urban form in mitigating the urban heat island effect: a UK case study. Build Environ 58:14-22

Krayenhoff ES, Voogt JA (2010) Impacts of urban albedo increase on local air temperature at daily-annual time scales: model results and synthesis of previous work. J Appl Meteorol Climatol 49:1634-1648

Memon AR, Leung YC D, Chunho L (2008) A review on the generation, determination and mitigation of urban heat island, J Environ Sci, Volume 20, Issue 1, 120-128

Middel A, Hab K, Brazel AJ, Martin CA, Guhathakurta S (2014) Impact of urban form and design on midafternoon microclimate in phoenix local climate zones. Landsc Urban Plan 122:16-28

Moonen P, Defraeye T, Dorer V, Blocken B, Carmeliet J (2012) Urban Physics: Effect of the micro-climate on comfort, health and energy demand, Frontiers of Architectural Research, Volume 1, Issue 3, September 2012, Pages 197-228, Issn 2095-2635

Oliveira S, Andrade H, Vaz T (2011) The cooling effect of green spaces as a contribution to the mitigation of urban heat: a case study in Lisbon. Build Environ 46:2186-2194

Santamouris M, Gaitani N, Spanou A, Saliari M, Giannopoulou K, Vasilakopoulou K, Kardomateas T (2012) Using cool paving materials to improve microclimate of urban areas - design realization and results of the flisvos project. Build Environ 53:128-136

Schär C, Vidale PL, Lüthi D, Frei C, Häberli C, Liniger MA, Appenzeller C (2004) The role of increasing temperature variability in European summer heatwaves. Nature 427:332-336

Skoulika F, Santamouris M, Boemi N, Kolokotsa S (2014) On the thermal characteristics and the mitigation potential of a medium size urban park in Athens, Greece. Landsc Urban Plan 123:73-86

Solecki WD, Rosenzweig C, Parshall L, Pope G, Clark M, Cox J, Wiencke M (2005) Mitigation of the heat island effect in urban New Jersey, Glob Environ Chang B Environ Hazards, Volume 6, Issue 1, 39-49

Souch C, Grimmond CSB (2004) Applied climatology: heatwaves. Prog Phys Geogr 28(4):599-606

Spronken-Smith RA, Oke TR (1998) The thermal regime of urban parks in two cities with different summer climates. International Journal of Remote Sens. 19:2085-2104

Spronken-Smith RA, Oke TR (1999) Scale modelling of nocturnal cooling in urban parks. Bound-Layer Meteorol 93:287-312

Steeneveld GJ, Koopmans S, Heusinkveld BG, Theeuwes NE (2014) Refreshing the role of open water surfaces on mitigating the maximum urban heat island effect. Landsc Urban Plan 121:92-96

Steinnocher K (1996) Integration of spectral and spatial classification methods for building a land-use model of Austria. Int Arch Photogramm Remote Sens 31:841-846

Sun J (2011) Vertical variations of mixing lengths under neutral and stable conditions during CASES99. J Appl Meteorol Climatol 50:2030-2041. doi:10.1175/JAMC-D-10-05006.1

Theeuwes NE, Solcerova A, Steeneveld GJ (2013) Modeling the influence of open water surfaces on the summertime temperature and thermal comfort in the city. J Geophys Res-Atmos 118:8881-8896

Upmanis H, Eliasson I, Lindqvist S (1998) The influence of green areas on nocturnal temperatures in a high latitude city (goteborg, Sweden). Int J Climatol 18:681-700

Upmanis H, Chen D (1999) Influence of geographical factors and meteorological variables on nocturnal urbanpark temperature differences. A case study of summer 1995 in Goteborg, Sweden. Climate Res 13:125-139

Willmott CJ (1981) On the validation of models. Phys Geogr 2:184-194

Wyngaard JC (2004) Toward numerical modeling in the "terra incognita". J Atmos Sci 61:1816-1826

Žuvela-Aloise M, Koch R, Neureiter A, Böhm R, Buchholz S (2014) Reconstructing urban climate of Vienna based on historical maps dating to the early instrumental period. Urban Clim 10:490-508 